\title{
CONVERSE TRENDS OF THE TERRESTRIAL AND GROUND WATER STORAGE CHANGES IN CANADA AND THE UNITED STATES
}

\author{
H. Wang ${ }^{1,2, *}$, L. Xiang ${ }^{1}$, H. Steffen ${ }^{3}$, P. Wu ${ }^{4}$, L. Jiang ${ }^{1}$, Q. Shen ${ }^{1}$, D.Piretzidis ${ }^{5}$, M. G. Sideris ${ }^{5}$, M. Hayashi ${ }^{4}$, L. Jia ${ }^{6}$ \\ ${ }^{1}$ State Key Laboratory of Geodesy and Earth's Dynamics, Institute of Geodesy and Geophysics, Chinese Academy of Sciences, \\ Xudong Street, Wuhan, China - whs@whigg.ac.cn \\ ${ }^{2}$ University of Chinese Academy of Sciences, Beijing, China - whs@ whigg.ac.cn \\ ${ }^{3}$ Lantmäteriet, 80182 Gävle, Sweden - holger.steffen@lm.se \\ ${ }^{4}$ Department of Geoscience, University of Calgary, Calgary T2N 1N4, Canada - (ppwu, hayashi) @ ucalgary.ca \\ ${ }^{5}$ Department of Geomatics Engineering, University of Calgary, Calgary T2N 1N4, Canada - (dimitrios.piretzidis, Sideris) \\ @ucalgary.ca \\ ${ }^{6}$ National Earthquake Infrastructure Service, Beijing 100036, China - iceagejia@163.com
}

Commission III, WG III/9

KEY WORDS: Canada and United States, Total water storage changes, Ground water storage changes, GRACE data, GPS data

\begin{abstract}
:
We study the terrestrial water storage (TWS) and groundwater storage (GWS) changes in Canada and United States. We employ the separation approach from Wang et al. (2013) together with the improved GRACE data of Release 6 for a longer time span until December, 2016. The TWS signals from lake levels are derived from satellite altimetry data over the lakes while TWS signals due to soil moisture (SM) and snow water equivalent (SWE) changes from hydrology models. There are four significant trend anomalies in North America for both TWS and GWS changes. Two positive anomalies are found in Canada with their centers in the provinces of Saskatchewan and Quebec, respectively, due to increased precipitation and/or increased runoff in their surroundings. Two negative anomalies are shown in the United States with their centers in California and the northwest of Texas, respectively, which are due to decreased precipitation and, especially for California, high water usage for agriculture.
\end{abstract}

\section{INTRODUCTION}

Continental water resources are influenced by climate change, drought and deluge, increasing water use, land use, and agricultural practices. Although, the spatial and temporal features in water storage can be monitored by the GRACE (Gravity Recovery and Climate Experiment) monthly data, the trend signal of hydrological changes in formerly glaciated areas (e.g. North America) is strong interfered by the effects of glacial isostatic adjustment (GIA) (Wang \& Wu, 2006a,b; Wang et al., 2008). The attempts to separate the hydrological trend signal from the total signal with GIA models are affected by the uncertainties of the glacial history and mantle viscosity in the GIA model. Fortunately, there are methods to estimate the trend of water storage changes reliably without using any GIA model (Wang et al. 2013,2015; Lambert et al. 2013; Li et al. 2018)

Wang et al. (2013) proposed a combination of GRACE gravity and Global Navigation Satellite System (GNSS) measurements to separate the terrestrial water storage (TWS) signals without any model assumption. They found that central North America had undergone a recovery in TWS after the extreme Canadian Prairies drought between 1999 and 2005 (Hanesiak et al., 2011) The largest rise in TWS was found southwest of Hudson Bay. In total, TWS in central North America increased by 43.0 $\pm 5.0 \mathrm{Gt} / \mathrm{a}$ from 2002 to 2010. The results uncovered the poorly known TWS on the North American continent. However, Wang et al. (2013) did not try to reduce the leakage effect due to harmonic truncation and Gaussian filtering in the estimation of the hydrology signal.

For this study, we focus not only on the total TWS changes but also on ground water storage (GWS) changes in Canada and United States. We employ the separation approach from Wang et al. (2013) but use the improved GRACE data of Release 6 for a longer time span until December, 2016, which improves the uncertainty of the separated TWS signals and eases the identification of time-variable features. The TWS signals from lake levels are estimated from satellite altimetry data over the lakes while TWS signals due to soil moisture (SM) and snow water equivalent (SWE) changes are calculated from hydrology models. Therefore, the GWS signals can be calculated. The theoretical framework (including the relevant equations) can be found in Wang et al. $(2013,2014)$.

\section{DATA SETS AND THE PROCESSING}

The ITSG RL06 SH solutions contain monthly Stokes coefficients from degree 2 to 90 from August, 2002 to December, 2016. They are frequently updated by the Institute of Geodesy of the Technische Universität Graz, Austria (MayerGürr et al., 2016).

Removal of correlated errors from GRACE monthly data is an important step for the accurate estimation of TWS changes. For a conventional destriping method (e.g., Swenson at al., 2006), a polynomial of selected degree $\mathrm{x}$ is used in a window of width $\mathrm{w}$, fitted to all the coefficients of the same parity in degrees y for a certain order (y), and the coefficients used in fitting are subtracted by the fitting values. In this way, the striping errors can be reduced in the coefficients within the window. The parameters $\mathrm{x}$ and $\mathrm{y}$ are empirically determined to be 2 and 8 respectively. Although the de-correlation filter can help reduce the stripe errors, they should be selectively applied only to correlated harmonic coefficients to avoid signal over-filtering. Piretzidis et al. (2018) therefore developed a method (DP method) that identifies the presence of correlated errors by utilizing the capabilities of machine learning algorithms, which are proven to be effective in Canada and Greenland by 
calculating monthly changes of equivalent water height and secular trends. The DP method results in improved recovery of mass changes with less geophysical signal attenuation, which can lead to a more accurate estimation of mass changes. Hence, our monthly coefficients are processed with the DP method for efficiently reducing the stripe noise.

Adding degree one coefficients and substitution of C20 coefficient are also necessary. The CM reference frame with its origin at the Earth's center of mass (CM) was used in the GRACE gravity field determination. In this frame, the degree one coefficients of surface TWS changes are undefined (Swenson et al., 2006; Wahr et al., 1998). However, the omission of the degree one information may probably have a significant impact on the estimation of TWS changes (e.g., Chen et al., 2005). Following Swenson et al. (2008), the degree one terms of TWS changes can be calculated based on degree one coefficients and the load Love number (Wang et al., 2012) for potential perturbation with respect to the $\mathrm{CF}$ frame with its origin at the center of figure (CF) of the Earth's outer surface. However, the degree one coefficients $(\mathrm{C} 10, \mathrm{C} 11$ and S11) have to be solved for the $\mathrm{CF}$ frame, which can be estimated with the GRACE-OBP approach (Swenson et al. 2008), from a combination of GRACE Stokes coefficients data for degrees two and higher and the output of an ocean bottom pressure model. Although the monthly $\mathrm{C} 20$ coefficients are available from GRACE gravity solutions, they are subjected to large uncertainties (Chen et al., 2016), presumably due to tide-like aliases, and thus usually replaced with estimates from other techniques, such as satellite laser ranging (SLR, Cheng and Tapley, 2004). We evaluate the linear trend of Stokes coefficients or gravity perturbations by accounting for periodic signals due to annual, 2.5 year and S2-tide (161 days) variations. Separation of TWS signal from GIA is a key step for this study. The GIA effects are removed from the monthly Stokes coefficients based on the approach proposed by Wang et al. (2013). By converting the GPS signal into a gravity signal according to Wahr et al. (1995) we can remove the GIA contribution from GRACE. GNSS networks that observe GIA induced uplift motion over a long-time span exist in North America. We expand observed uplift displacement trends from at least a decade of GNSS data (1993-2006 in North America (Sella et al., 2006; Peltier et al., 2015) into spherical harmonics with degrees up to 90 . The remaining signal shows the TWS contribution only.

The average soil moisture data from 2002 to 2016 are from two land surface models: NOAH and VIC of GLDAS (Rodell et al., 2004). The average SWE data are used from the three land surface models: CLM, MOSIC and VIC of GLDAS during the same period. GLDAS data are available from the Goddard Earth Sciences Data and Information Services Center (http://disc.gsfc.nasa.gov/hydrology). The monthly coefficients of the average SM or SWE data are computed for degrees/orders up to 90 , and are removed from the GRACE Stokes coefficients so that the residuals give the contributions from the GWS changes.

Inversion is necessary to recover a final mascon solution. If the TWS or GWS changes are calculated by spherical harmonic synthesis as described by Wahr et al. (1998), the results are inevitably affected by signal leakages due to the truncation of higher harmonic degree terms and necessary smooth filtering (e.g, using Gaussian filter (Jekeli, 1981)). The way used here is the mascon fitting treatment (Jacob et al., 2012), which can avoid the problem to a large degree. The uncertainties are estimated by considering 2 aspects: 1) the values of the TWS changes on the ocean for the same latitudes as in North America; 2) the differences among the different hydrology models used.
However, smooth filtering is an important step in order to reduce measured noise for the high order Stokes coefficients data. Here, we use a $220-\mathrm{km}$ Gaussian filter in the mascon fitting inversion.

Time series of the GRACE-derived hydrological variation in selected areas are compared to time series of terrestrial data from groundwater wells. The majority of the data covers the time span since 2000. Groundwater levels for Manitoba, Saskatchewan and Alberta have been kindly provided upon request by the Water Stewardship Division of Government Manitoba, the Saskatchewan Water Authority and the Groundwater Information Centre of Government Alberta, respectively. The groundwater data have all been checked for significant outliers and anthropogenic influences before they are used to validate our mascon estimate of TWS and GWS changes.

\section{RESULTS AND CONCLUSIONS}

Trend rates of the separated TWS changes in North America are shown in Figure 1. The component signals for lake water level, soil moisture and SWE derived from hydrology models are shown in Figures 2 to 4 respectively. The results for the separated GWS changes are shown in Figure 5.

We present 1-degree-grid mascon solutions for the TWS and GWS changes (Figure 6 and Figure 7 respectively) (i.e., monthly changes and the trends) from August, 2002 to December, 2016 in North America, and find different features in Canada and the United States. There are four significant trend anomalies in North America for both TWS and GWS changes. Two positive anomalies are found in Canada with their centers in the provinces of Saskatchewan and Quebec, respectively, due to increased precipitation and/or increased runoff in their surroundings. Two negative anomalies are visible in the United States with their centers in California and the northwest of Texas, respectively, which are due to decreased precipitation and, especially for California, high water usage for agriculture. For the TWS mascon solution, the four anomalies have magnitudes of $29.7,11.3,47.0$ and $21.3 \times 10^{-3} \mathrm{~m} / \mathrm{yr}$., respectively. For the GWS mascon solution, they are 32.6, 25.6, 45.6 and $22.8 \times 10^{-3} \mathrm{~m} / \mathrm{yr}$. Note that the first three anomalies are located in upper- or middle-stream areas. The Saskatchewan anomaly reflects the increasing trends of TWS and GWS after the extreme Canadian Prairies drought. Our mascon solutions for the GWS changes in the Canadian Prairies are well validated by well level data. The increased total TWS mass per year in the North America amounts to $15.1 \mathrm{Gt}$ while the increased total GWS mass per year is $44.6 \mathrm{Gt}$.

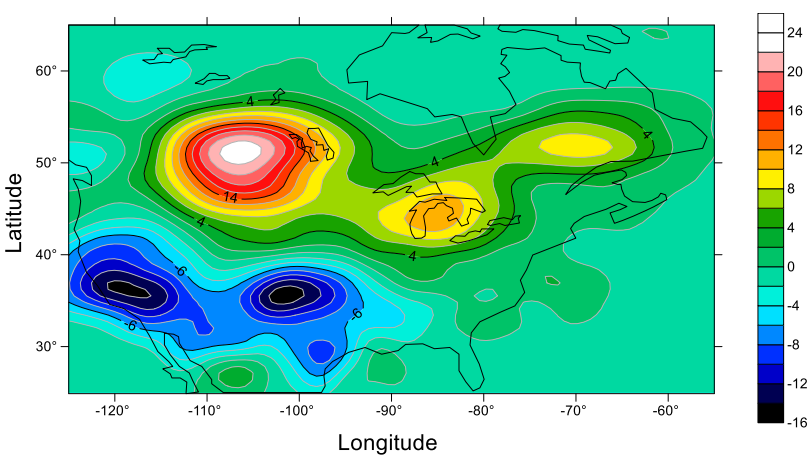

Figure 1. Trend rates of the separated TWS changes in North America $\left(\mathrm{x} 10^{-3} \mathrm{~m} / \mathrm{yr}\right.$.) 


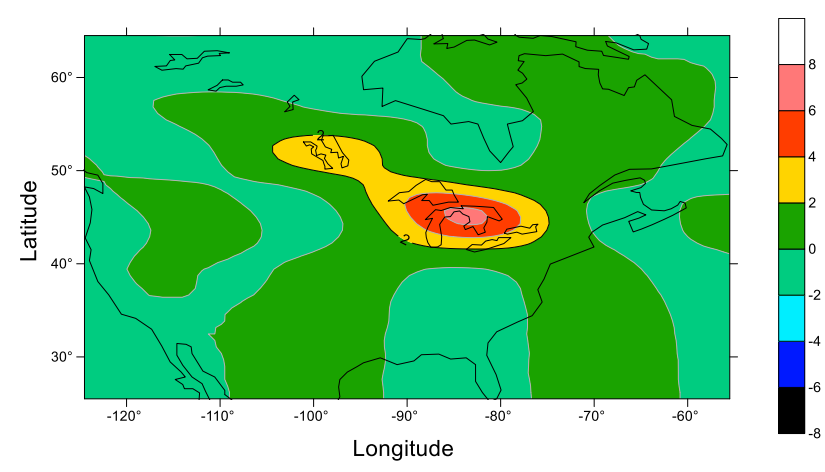

Figure 2. Trend rates of the lake water level changes in North America (x10-3 m /yr.)

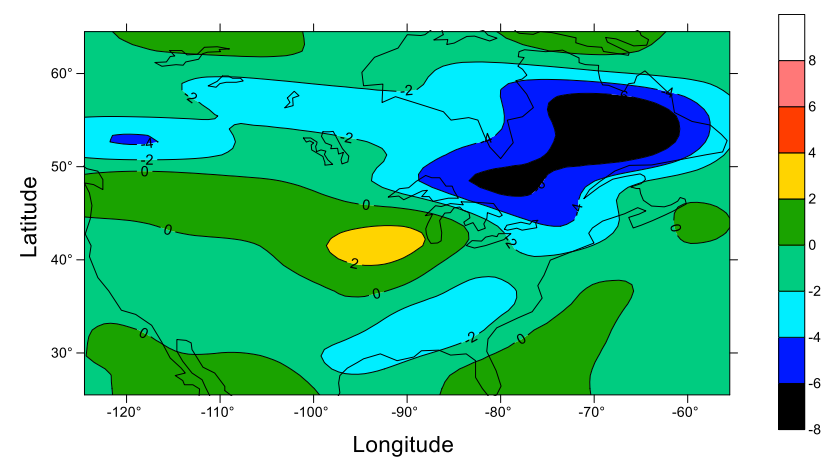

Figure 3. Trend rates of the soil moisture changes in North America $\left(\times 10^{-3} \mathrm{~m} / \mathrm{yr}\right.$.

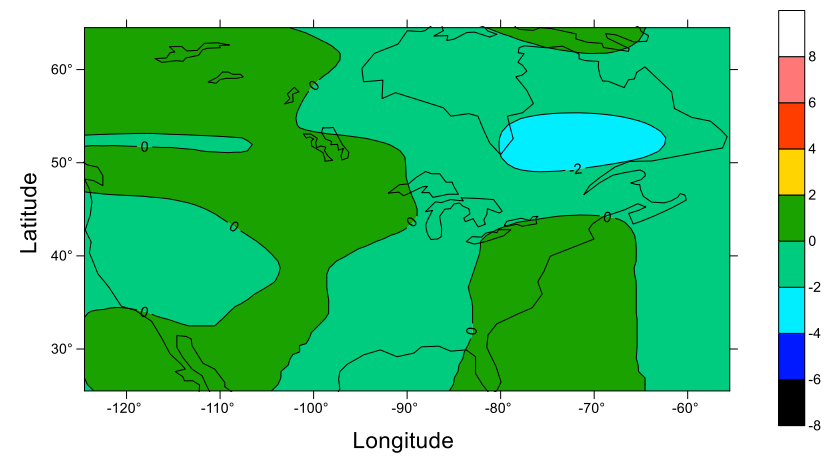

Figure 4. Trend rates of the SWE changes in North America $\left(\mathrm{x} 10^{-3} \mathrm{~m} / \mathrm{yr}\right.$.)

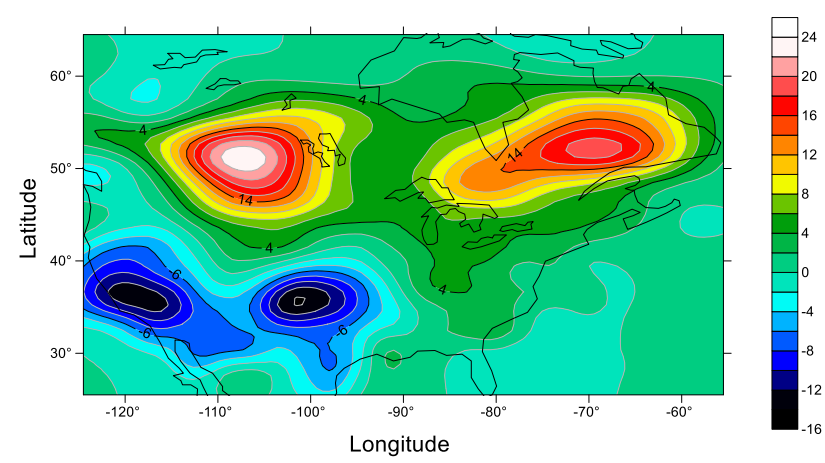

Figure 5. Trend rates of the separated GWS changes in North America $\left(\times 10^{-3} \mathrm{~m} / \mathrm{yr}\right.$.)

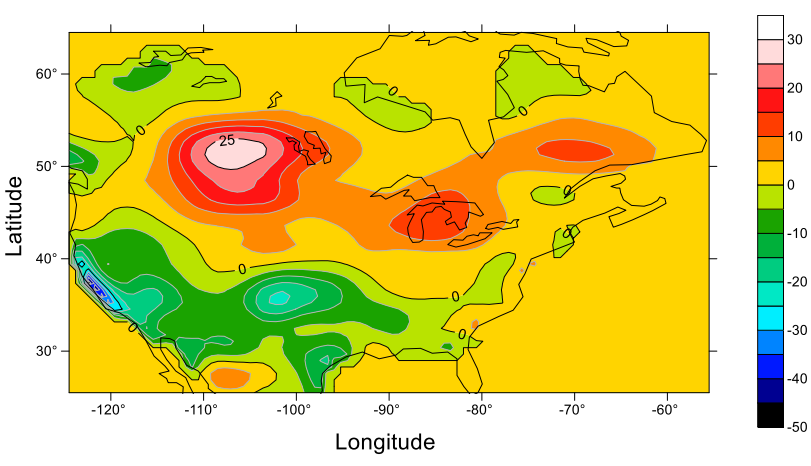

Figure 6. Mascon solution for the trend rates of the separated TWS changes in North America $\left(\times 10^{-3} \mathrm{~m} / \mathrm{yr}\right.$.)

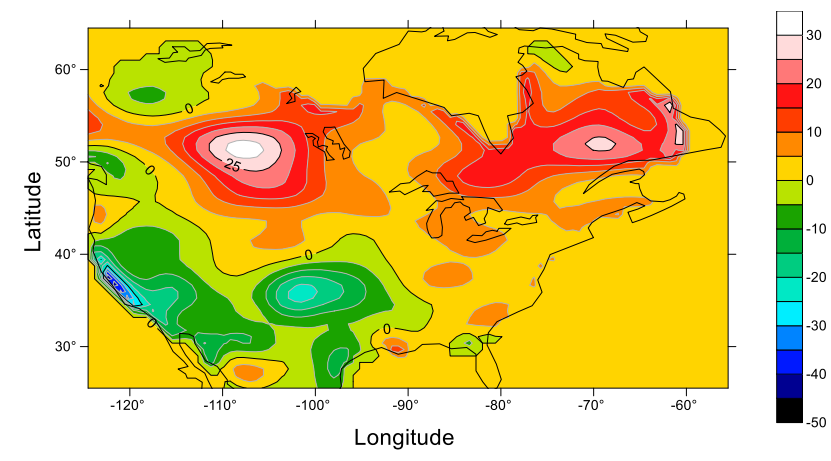

Figure 7. Mascon solution for the trend rates of the separated GWS changes in North America $\left(\times 10^{-3} \mathrm{~m} / \mathrm{yr}\right.$.)

\section{ACKNOWLEDGEMENTS}

This work is funded by the National Key R \& D Program of China (2017YFA0603103), the National Natural Science Foundation of China (41431070, 41590854 and 41621091), Key Research Program of Frontier Sciences, CAS (QYZDBSSW-DQC042 and QYZDJ-SSW-DQC027), the Hong Kong Research Grants Council (17315316 and 17305314) and Alberta Innovates (the Groundwater Recharge in the Prairies project).

\section{REFERENCES}

Chen, J.L., Rodell, M., Wilson, C.R., Famiglietti, J.S., 2005. Low degree spherical harmonic influences on Gravity Recovery and Climate Experiment (GRACE) water storage estimates. Geophys. Res. Lett., 32, L14405.

Chen, J. L., Wilson, C., Ries, J., 2016. Broad-band assessment of degree-2 gravitational changes from GRACE and other estimates, 2002-2015. J. Geophys. Res. Solid Earth, 121, 21122128.

Cheng, M., Tapley, B. D., 2004. Variations in the Earth's oblateness during the past 28 years. Journal of Geophysical Research, 109, B09402.

Hanesiak, J. M., Stewart, R. E., Bonsal, B. R., et al., 2011. Characterization and summary of the 1999-2005 Canadian Prairie Drought. Atmosphere-Ocean, 49, 421-452.

Jekeli, C., 1981. Alternative methods to smooth the Earth's gravity field. Rep. 327, Dep. of Geod. 557 Sci. and Surv., Ohio State Univ., Columbus. 
Lambert, A., Huang, J., van der Kamp, G., et al., 2013. Measuring water accumulation rates using GRACE data in areas experiencing glacial isostatic adjustment: The Nelson River basin. Geophysical Research Letters, 40, 1-5.

Li, T, Wu, P,, Wang, H., Jia, L., Steffen, H., 2018. Hydrology signal from GRACE gravity data in the Nelson River basin, Canada: a comparison of two approaches. Earth, Planets and Space, 70, 41-53.

Mayer-Gürr, T., Behzadpour, S., Ellmer, M., Kvas, A., Klinger, B., Zehentner, N., 2016. ITSG-Grace2016-Monthly and Daily Gravity Field Solutions from GRACE. GFZ Data Services. http://doi.org/10.5880/icgem.2016.007

Peltier, W. R., 2004. Global glacial isostasy and the surface of the ice age earth: the ICE-5G (VM2) Model and GRACE. Annual Review of Earth and Planetary Sciences, 32, 111-149.

Peltier, W. R., Argus, D. F., Drummond, R., 2015. Space geodesy constrains ice-age terminal deglaciation: The global ICE-6G_C (VM5a) model. J. Geophys. Res. Solid Earth, 120, 450-487.

Piretzidis, D., Sra, G., Karantaidis, G., Sideris, M. G., Kabirzadeh, H., 2018. Identifying presence of correlated errors using machine learning algorithms for the selective decorrelation of GRACE harmonic coefficients. Geophysical Journal International, 215(1), 375-388.

Rodell, M., Velicogna, I., Famiglietti, J. S., 2009. Satellitebased estimates of groundwater depletion in India. Nature, 460, 999-1002.

Sella, G. F., Stein, S., Dixon, T. H., et al., 2007. Observation of glacial isostatic adjustment in "stable" North America with GPS. Geophysical Research Letters, 34, L02306.

Swenson, S., Chambers D., Wahr, J., 2008. Estimating Geocenter Variations from a Combination of GRACE and Ocean Model Output. J Geophys Res, 113: B08410

Swenson, S., Wahr, J., 2006. Post-processing removal of correlated errors in GRACE data. Geophysical Research Letters, 33: L08402.

Wahr, J., Han, D. \& Trupin, A., 1995. Predictions of vertical uplift caused by changing polar ice volumes on a viscoelastic earth. Geophys. Res. Lett., 22(8), 977-980.

Wahr, J., Molenaar, M., Bryan, F., 1998. Time variability of the Earth's gravity field: Hydrological and oceanic effects and their possible detection using GRACE. Journal of Geophysical Research, 103(B12), 30205-30229.

Wang, H., Jia, L., Steffen, H., et al., 2013. Water storage increase in North America and Scandinavia from GRACE gravity data. Nature Geoscience, 6(1), 38-42.

Wang, H., Wu, P., van der Wal, W., 2008. Using postglacial sea level, crustal velocities and gravity-rate-of-change to constrain the influence of thermal effects on mantle lateral heterogeneities. Journal of Geodynamics, 46, 104-117.
Wang, H., Wu, P., 2006a. Effects of lateral variations in lithospheric thickness and mantle viscosity on glacially induced surface motion on a spherical, self-gravitating Maxwell Earth. Earth and Planetary Science Letters, 244, 576-589.

Wang, H., Wu, P., 2006b. Effects of lateral variations in lithospheric thickness and mantle viscosity on glacially induced relative sea levels and long wavelength gravity field in a spherical, self-gravitating Maxwell Earth. Earth and Planetary Science Letters, 249, 368-383.

Wang, H., Xiang, L., Jia, L., et al., 2012. Load Love numbers and Green's functions for elastic Earth models PREM, iasp91, ak135, and modified models with refined crustal structure from Crust 2.0. Computers \& Geosciences, 49, 190-199.

Wang, H., Xiang, L., Jia, L., Wu, P. Steffen, H., Jiang, L., Shen, Q., 2015. Water storage changes in North America retrieved from GRACE gravity and GPS data. Geodesy and Geodynamics, 6(4), 267-273.

Revised Appril 2019 